\title{
Extending the Measurement of Graduate Admission Abilities Beyond the Verbal and Quantitative Domains
}

\author{
Donald E. Powers and Spencer S. Swinton \\ Educational Testing Service
}

Traditionally, major national admissions tests, such as the Graduate Record Examinations (GRE) Aptitude Test, have focused primarily on the measurement of broadly applicable verbal and quantitative abilities. The GRE Board recently sponsored an investigation of the possibility of extending the measurement of abilities beyond the verbal and quantitative domains in order to facilitate a broadened definition of talent. That effort resulted in a restructured GRE Aptitude Test, which includes a measure of analytical ability for which a separate score is reported. The present study provides a factor analytic description of the new restructured test. Results suggest that the restructured test continues to tap the verbal and quantitative skills measured by the original GRE Aptitude Test but that it also contains a distinct, identifiable analytical dimension that is highly correlated with the dimensions underlying performance on the verbal and quantitative sections of the test.

Despite the complexity in the ability domain (see, e.g., Carroll \& Maxwell, 1979), standardized tests of general academic ability have tended to focus almost exclusively on the measurement of two broadly applicable abilities-developed verbal and quantitative aptitude-and with good reason. These two constructs have been shown to be not only logically but also empirically related to successful study

APPLIED PSYCHOLOGICAL MEASUREMENT Vol. 5, No. 2, Spring 1981, pp. 141-158

(C) Copyright 1981 Applied Psychological Measurement Inc. 0146-6216/81/020141-18\$1.90 in a variety of fields (Willingham, 1974, 1976; Wilson, 1979).

The purpose of one such test of general academic ability, the Graduate Records Examinations (GRE) Aptitude Test, is to facilitate the selection of graduate school candidates. Until the fall of 1977, the test consisted of a verbal ability measure designed to test, according to Conrad, Trisman, and Miller (1977), "the ability to understand and manipulate written words in order to solve problems" (p. 10) and a quantitative ability measure designed to test "basic mathematical skills, understanding of elementary mathematical concepts, and ability to reason quantitatively and solve problems in a quantitative setting" (p. 14). The verbal section contained four principal item types: antonyms, analogies, sentence completions, and reading comprehension sets. The quantitative section consisted of three types: discrete mathematics, data interpretation, and quantitative comparison.

\section{The Restructuring Effort}

In 1974 a plan was developed to improve the GRE Aptitude Test by broadening its definition of academic talent beyond verbal and quantitative abilities (Altman, Carlson, \& Donlon, 1975) in order to allow students to demonstrate a broader range of skills. After a survey of consti- 
tuents revealed that faculty and administrators, as well as students, were most receptive to revising the test to include a measure of analytical or abstract reasoning skills, seven analytical item types were developed and evaluated with respect to a number of standards including reliability, efficiency, criterion-related validity, face validity, difficulty, speededness, and independence of verbal and quantitative measures (Conrad, 1976; Altman \& Conrad, 1976). As a result, three analytical item types were selected for inclusion in the current measure of analytical skills, which has been a part of the GRE Aptitude Test since October 1977. The measure is described as tapping students' abilities to recognize logical relationships, to judge the consistency of interrelated statements, to use a sequential procedure to eliminate incorrect choices in order to reach a conclusion, to make inferences from statements expressing relationships among abstract entities such as nonverbal or nonnumerical symbols, and to determine relationships between independent or interdependent categories or groups. From 1977 until now, these abilities have been measured by three principal item types: analysis of explanations, logical diagrams, and analytical reasoning (Conrad et al., 1977), which are illustrated in Table 1. Substitutions for or modifications to these item types may be made before the analytical measure becomes fully operational.

\section{Objectives}

The major purpose of the study reported here was to develop a factor analytic description of the restructured GRE Aptitude Test. The methodology of factor analysis has been considered to be a useful approach to establishing the construct validity of measurement instruments (Cronbach, 1971). However, it is recognized that evidence of construct validity comes, not from a single study, but from a variety of related research efforts (American Psychological Association, 1974). The study reported here represents a correlational approach to establishing construct validity.
The secondary purposes of the investigation were (1) to provide additional information relevant to guiding the development of additional parallel forms of the analytical measure and (2) to compare the structure of the original test with the restructured test. Overall, this study was intended to provide some information relevant to the degree of progress toward the goal of broadened measurement of student talent.

\section{Procedures}

\section{The Sample}

Analyses reported here were based on a national random sample of approximately 4,000 examinees who took one form of the restructured GRE Aptitude Test during its first operational administration in October 1977. The item-level responses to all 205 items comprising the test constituted the raw data for the study. Other preliminary analyses also used the itemlevel responses of another random sample of nearly 6,000 examinees who took an equivalent form of the restructured test during the same administration.

\section{Analyses}

Analyses were performed in two stages. Preliminary item-level analyses of only the analytical sections of each of two equivalent forms of the test were conducted to gain a better understanding of the finer dimensions that might distinguish among the analytical items. Results of these analyses were seen as potentially relevant for developing tighter specifications for the new analytical measure. Analyses of two forms were used to assess the degree to which the new analytical forms had been successfully balanced on the basis of initial test specifications.

A second preliminary item-level solution was also obtained for one form using all verbal, quantitative, and analytical items. This solution was used, with test specifications, to form clusters of verbal, quantitative, and analytical items for the later parcel-based analyses. Matrices of 


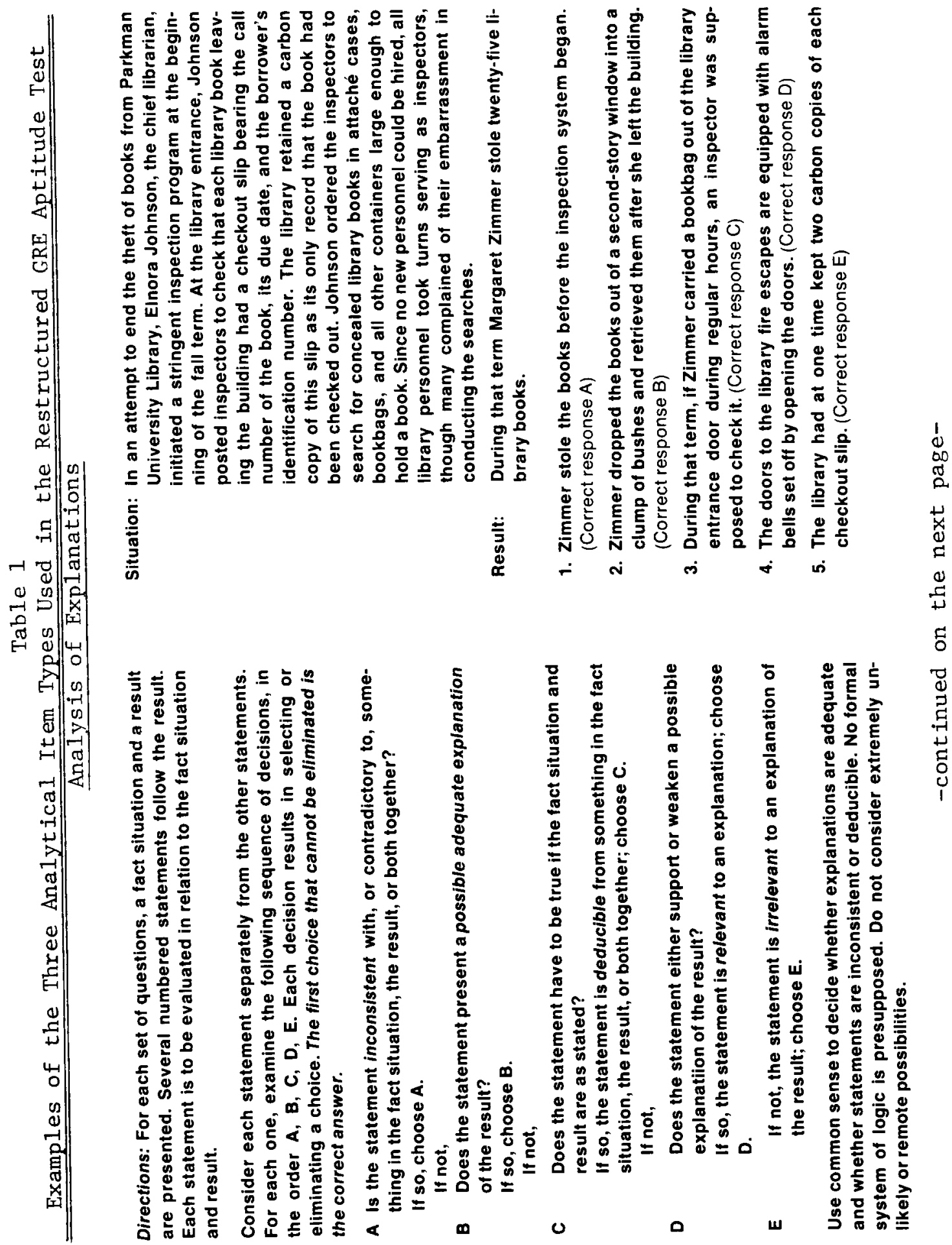



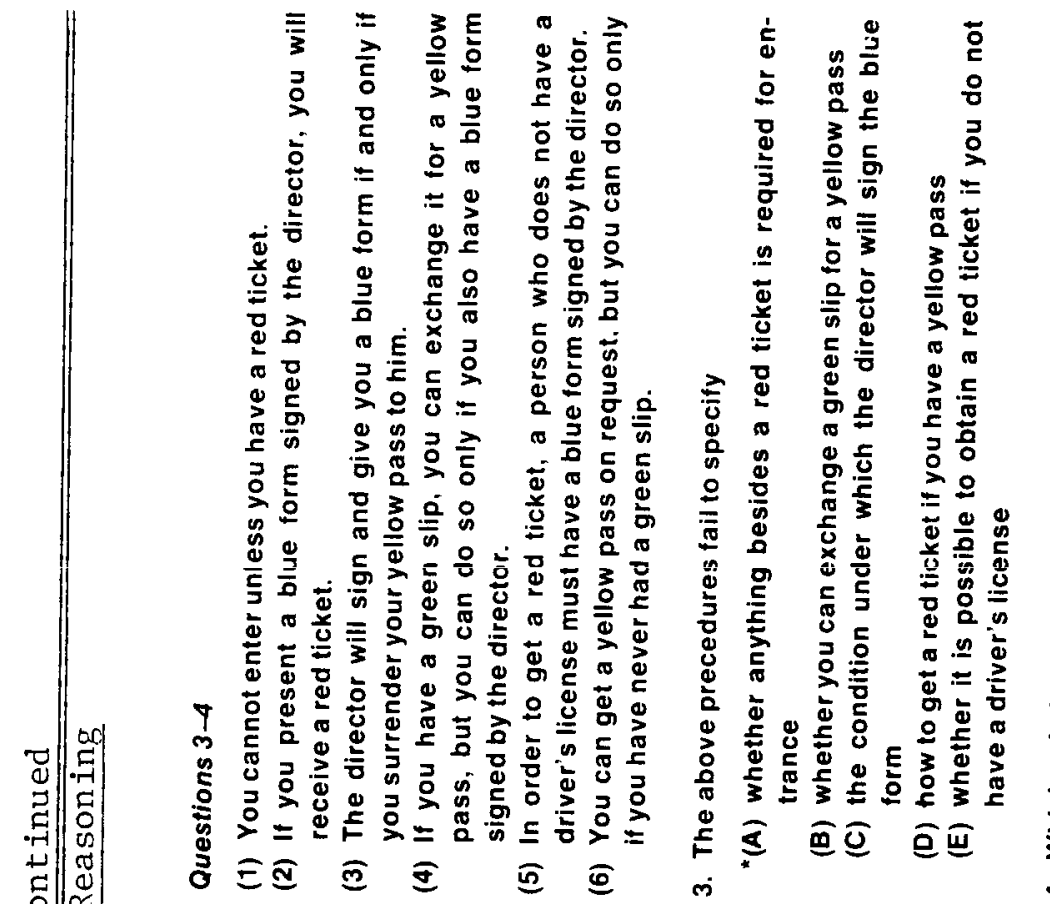

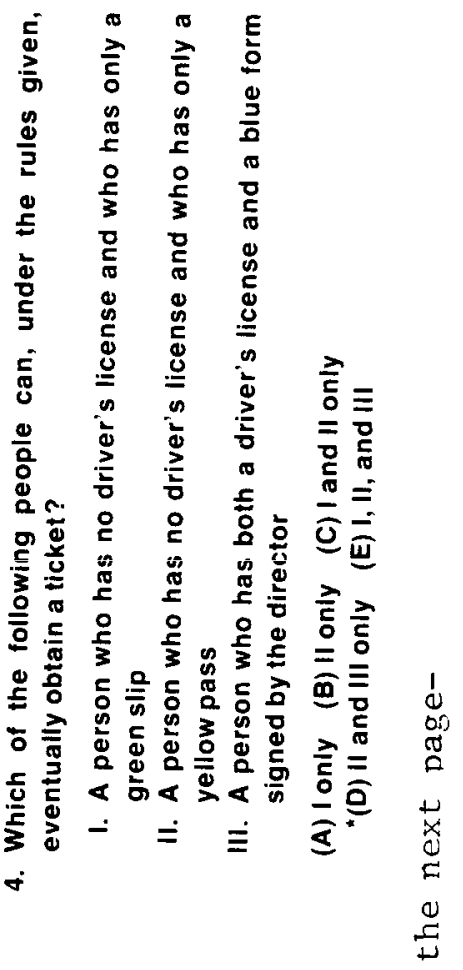
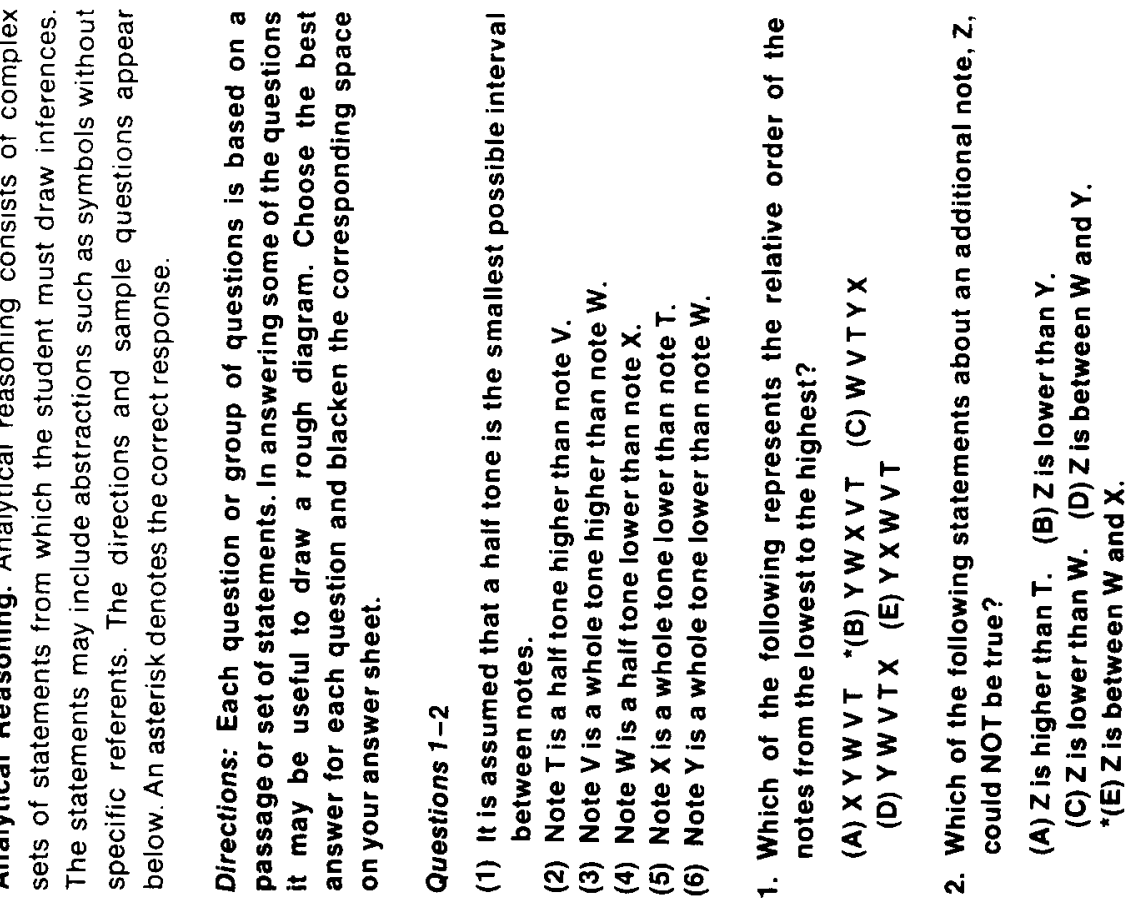

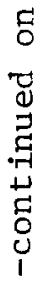




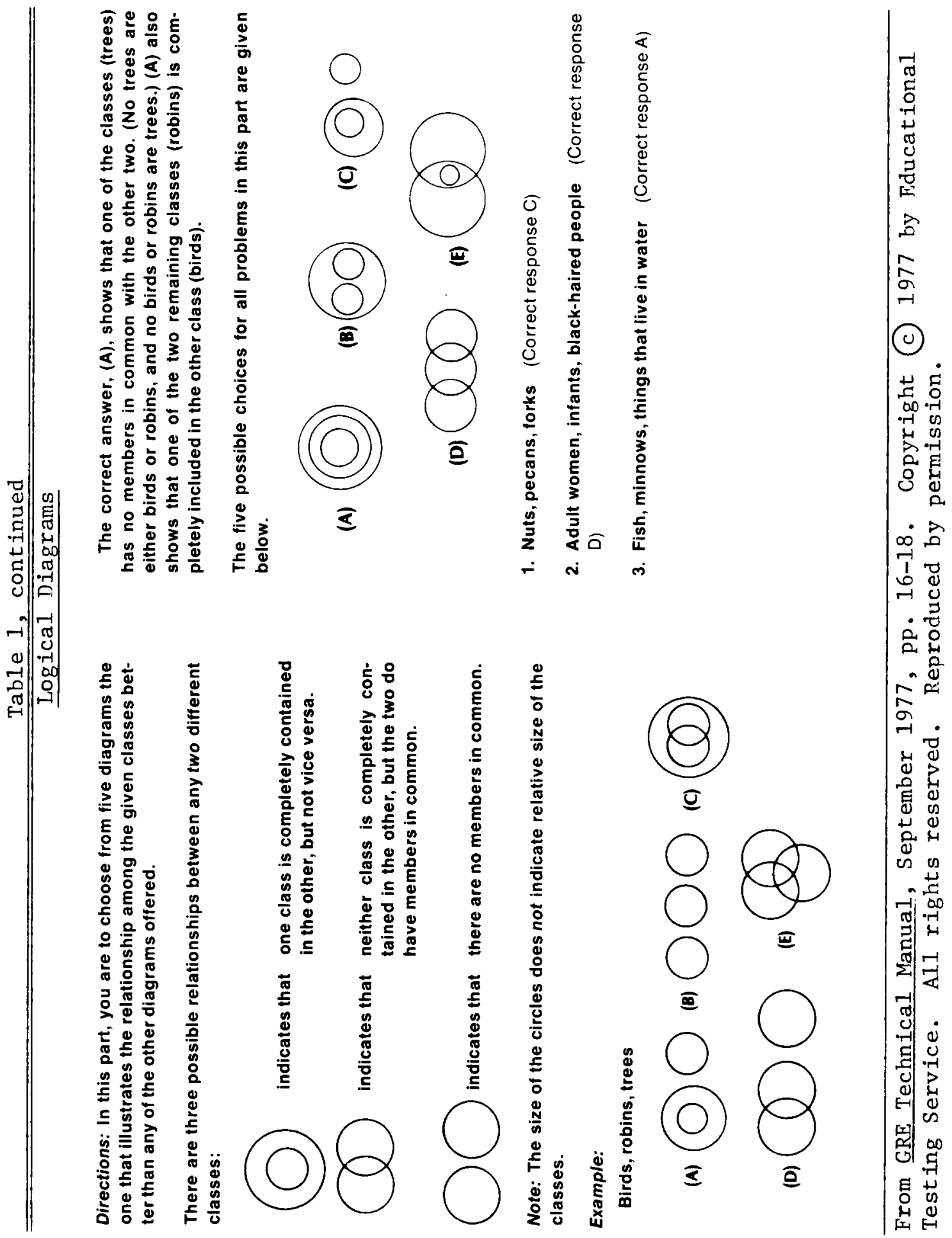


tetrachoric coefficients were subjected to initial principal axis factoring to determine the approximate number of factors to be retained in each case. Both the magnitude of eigenvalues and the breaks in their size were used to decide the appropriate number of factors to be designated for subsequent minres solutions (Harman \& Jones, 1966) from which communality estimates were produced. The resulting factors were rotated according to several rotational schemes, both orthogonal and oblique, including varimax (Kaiser, 1958), oblimin (Jennrich \& Sampson, 1966), and geoplane (Yates, 1974, 1978, 1979). ${ }^{1}$ These first-stage exploratory analyses not only served to better understand the more molecular dimensions underlying performance on the test but also formed the basis for specifying homogeneous subsets or parcels of items upon which the major second-stage analyses were based.

The use of item parcels was preferred for several reasons but mainly to circumvent some of the problems often encountered in using interitem correlations. For example, it is commonly held that spurious difficulty factors may arise from item-level factor analyses. Nonlinearity may lead to the emergence of some factors defined by easy items and others marked by difficult items, even though the underlying continuum is unidimensional. In addition, parcel sub-

\footnotetext{
'Geoplane is a hyperplane-location approach that yields an oblique solution. The objective of cluster-oriented rotational schemes (such as varimax and oblimin) is usually to associate each variable with a single factor. Under the geoplane criterion, factors are defined by virtue of the set of variables to which they are unrelated and the variables themselves are permitted to be factorially complex. Greater freedom exists in the choice of factor axes when planes or hyperplanes, rather than reference axes, are chosen to represent clusters of variables (Harman, 1976, p. 96). The geoplane criterion "encourages" variables to be of less than full factorial complexity but does not "force" any of them to be unifactorial as the cluster-oriented schemes are prone to do. On the contrary, the geoplane criterion, by minimizing the geometric mean of squared loadings of variables on factors, demands only that each variable have a near-zero loading on at least one factor (i.e., that each lie in a hyperplane not containing some factor).
}

scores are more reliable than individual items and should therefore be less susceptible than the latter to the emergence of difficulty factors arising from instability, although nonlinearities arising from guessing are not removed by combining items. Finally, the reporting of results based on a smaller number of parcels is less cumbersome than one based on a larger number of items.

The rationale for using subsets of items here parallels a solution to the item versus subset controversy given by Cattell and Burdsal (1975), who cite two fundamental approaches to forming item parcels. The first, grouping of items by apparent content, is rejected as being too subjective; the second, grouping items according to their intercorrelations, is dismissed as being somewhat destructive of inherent simple structure. Their recommendation to perform two factor analyses-one based on individual items and the other on the parcelled item variables that result from the item-level factoring-has been followed in this study.

In specifying the item parcels for the secondlevel analysis, certain decisions were needed. When certain item characteristics were confounded with item type (e.g., reading comprehension items tended to be less difficult than vocabulary items), clustering based on only one attribute effectively foreclosed the possibility that other attributes might define factors. The prior item-level factoring, however, allowed rational choices in assigning items to parcels so as not to mask certain important sources of variance suggested from the initial analyses. Important sources of variance that emerged from these initial analyses were nominal item type, item difficulty within certain item types, keyed response choice for certain fixed-format items, content for certain items (e.g., algebraic, geometric, or arithmetic content for mathematics items), and passage, or diagram, dependencies for certain items. Since the evidence for speed factors was weak in the item-level results, the position of items at the end of separately timed sections was not considered in specifying parcels. The item-level results have been reported in detail elsewhere 
(Swinton \& Powers, 1979). Thus, except for speededness, all dimensions that had emerged from item-level analyses were afforded the opportunity to appear in item parcels.

The 205 items were divided into 53 item parcels consisting of either three or (in most cases) four items. Except for using product-moment correlations instead of tetrachoric coefficients, all item parcels were subjected to the same factor analytic procedures used to analyze the itemlevel data.

Finally, item-parcel solutions, based on both varimax and geoplane rotations, were extended to background information (Dwyer, 1937; Harman, 1938) to facilitate the interpretation of factors. The results of this extension analysis have also been described in more detail elsewhere (Swinton \& Powers, 1979).

\section{Results}

The item-parcel groupings that resulted from preliminary item-level analyses are shown in Table 2, which also shows the number of items in each parcel as well as the mean and standard deviation of scores for each parcel. The largest eigenvalues resulting from a principal components analysis of these parcels were 33.29 , $6.23,3.66,2.34,1.62,1.39,1.09,1.05, .91$, and .81. Although eight eigenvalues were greater than one, the application of a scree test (Cattell, 1966) suggested that six factors would be appropriate. Three, four, five, and six factors were rotated and examined before the final decision was made to base the description of item parcels on the six-factor solution. A final six-factor minres solution, which accounted for $90.4 \%$ of the total estimated common variance, was rotated according to the oblimin, varimax, and geoplane criteria. Only the results of the latter two rotations are presented here, since the oblimin rotation (Swinton \& Powers, 1979) did not yield a reasonable simple structure.

\section{Varimax Solution}

The varimax rotation produced three substantial factors, which accounted for nearly $80 \%$ of the common variance, and three less prominent factors, each accounting for about $7 \%$ of the common variance (see Table 3 ).

The communalities computed for the item parcels, although not as high as those usually reported for longer tests, were in general higher than those computed for the item-level solutions. Approximately $57 \%$ of the item cluster communalities were greater than .40 , compared with about $46 \%$ of the item-level communalities. Furthermore, only about $11 \%$ of the parcel communalities were very low (less than .30), compared with $28 \%$ of those computed for individual items. Thus, there is some evidence for the greater reliability of clusters of items.

Factor I, reflecting $31.1 \%$ of the total common variance, was defined by high loadings from sentence completions, reading comprehension items, and two analytical item types. High loadings on this factor were also noted for several parcels of easy discrete verbal items (antonyms and analogies). Factor I was labeled "verbal reasoning." Because the similarity of analysis of explanation items to reading comprehension items in their use of questions with narrative passages is apparent, it is probably not surprising that these two item types should load on a common factor. However, the fact that logical diagram items also helped define Factor I is somewhat more problematic, suggesting perhaps that this factor also reflects a more general verbal and classificatory reasoning ability.

Factor II accounted for slightly more than $25 \%$ of the common variance. Because of high loadings from nearly all quantitative parcels, it was termed "general quantitative ability." Similar to Factor I, however, this factor also had some relatively high loadings from analytical item parcels.

Factor III, reflecting $22.8 \%$ of the total common variance, was defined primarily by loadings from antonym and analogy items, especially the more difficult ones, and was thus viewed as a "vocabulary" factor. A few substantial loadings also came from sentence completions and reading comprehension items employing relatively difficult vocabulary. 
Table 2

Item Parcel Designations and Their Means and Standard Deviations

\begin{tabular}{|c|c|c|c|c|}
\hline \multirow[b]{2}{*}{ Number } & \multirow[b]{2}{*}{ Name } & Number & \multicolumn{2}{|l|}{ Mean No. } \\
\hline & & of Items & Correct & S.D. \\
\hline \multicolumn{5}{|l|}{ Verbal } \\
\hline 1 & $\mathrm{SC}$ (easy) & 4 & 2.98 & 1.04 \\
\hline 2 & SC (easy) & 4 & 2.95 & 1.06 \\
\hline 3 & SC (difficult) & 4 & 1.94 & 1.18 \\
\hline 4 & SC (difficult) & 4 & 1.39 & 1.24 \\
\hline 5 & AN (easy) & 4 & 1.80 & 1.25 \\
\hline 6 & $\mathrm{AN}$ (easy) & 4 & 3.28 & .88 \\
\hline 7 & AN (difficult) & 4 & .85 & 1.04 \\
\hline 8 & AN (difficult) & 4 & .77 & 1.03 \\
\hline 9 & OPP (very difficult) & 4 & .52 & .91 \\
\hline 10 & OPP (difficult) & 4 & .93 & 1.02 \\
\hline 11 & OPP (mid difficult) & 4 & 1.73 & 1.25 \\
\hline 12 & OPP (easy) & 4 & 1.85 & 1.35 \\
\hline 13 & OPP (very easy) & 4 & 3.23 & 1.02 \\
\hline 14 & $\mathrm{RCPl}$ & 3 & 2.43 & .80 \\
\hline 15 & $\mathrm{RCP} 2$ & 3 & 1.74 & .88 \\
\hline 16 & RCP3 (difficult) & 4 & 2.20 & 1.37 \\
\hline 17 & RCP3 (easy) & 4 & 2.87 & 1.19 \\
\hline 18 & $\mathrm{RCP} 4$ & 3 & 1.47 & 1.03 \\
\hline 19 & RCP5 (difficult) & 4 & 1.85 & 1.49 \\
\hline 20 & $\operatorname{RCP} 5$ (easy) & 4 & 2.75 & 1.48 \\
\hline \multicolumn{5}{|c|}{ Quantitative } \\
\hline 21 & QC choice D (difficult) & 3 & .90 & .88 \\
\hline 22 & QC choice D (easy) & 3 & 1.77 & .96 \\
\hline 23 & QC choice $A, B, C$ (very difficult) & 4 & 1.13 & 1.08 \\
\hline 24 & QC choice A,B,C (difficult) & 4 & 1.68 & 1.09 \\
\hline 25 & QC choice $A, B, C$ (mid difficult) & 4 & 2.54 & 1.00 \\
\hline 26 & QC choice $A, B, C$ (easy) & 4 & 3.07 & 1.00 \\
\hline 27 & QC choice A, B, C (easy) & 4 & 3.28 & .96 \\
\hline 28 & QC choice A,B,C (very easy) & 4 & 3.70 & .65 \\
\hline 29 & DI & 4 & 2.96 & 1.10 \\
\hline 30 & DI extraction & 3 & 2.21 & 1.02 \\
\hline 31 & DI manipulation & 3 & 1.60 & 1.10 \\
\hline 32 & $Q$ (easy) & 3 & 2.16 & .79 \\
\hline 33 & GEOM & 4 & 1.69 & 1.19 \\
\hline 34 & $\mathrm{ALG}$ & 4 & 1.14 & .98 \\
\hline 35 & Word Problems & 4 & 1.94 & .92 \\
\hline
\end{tabular}

-continued on the next page- 
Table 2, continued

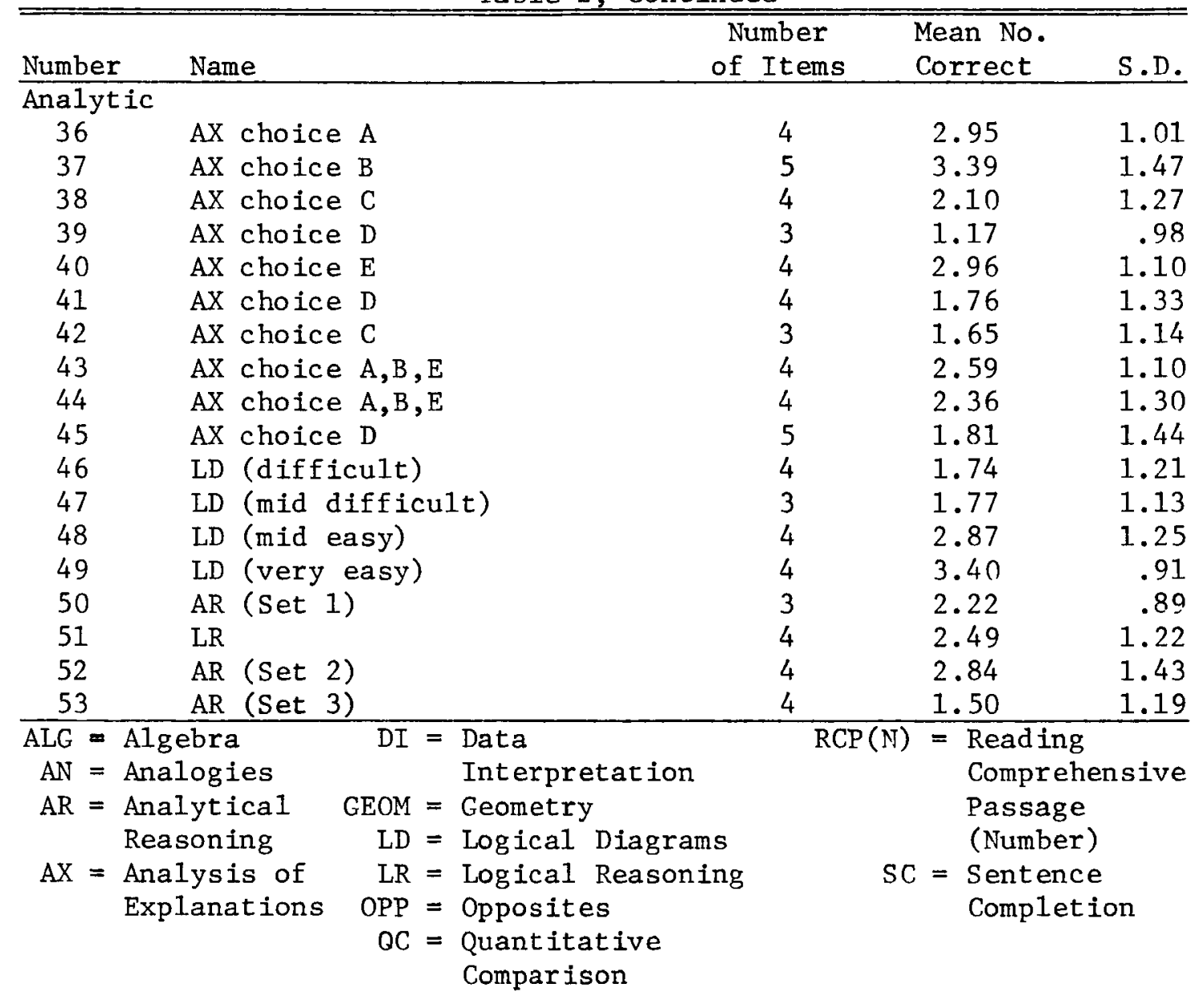

Factor IV had very high loadings from two parcels based on items associated with a technical reading passage. This factor accounted for $7.1 \%$ of the test's common variance.

Factor V, which also represented about $7 \%$ of the total common variance, is quantitative in nature, primarily reflecting performance on three parcels of "data interpretation" items.

Factor VI also accounted for nearly $7 \%$ of the Aptitude Test's common variance and was defined as "analytical ability" by virtue of high loadings from nearly all of the analytical item parcels but from none of the verbal or quantitative item parcels.
Thus, the orthogonal varimax rotation of factors based on item parcels yielded three major factors, the first of which covaried strongly with verbal items, particularly reading comprehension and sentence completion items (which also tend to be somewhat easier than are most discrete verbal items), and with analytical items. The second factor covaried with both quantitative items and analytical items. Thus, from this solution, it would appear that analytical items are essentially describable in terms of verbal and quantitative factors but not vocabulary factors, and that these items show only modest variation that can be described as unique to their item 
Table 3

Varimax Factor Loadings for Item Parcel Analysis

\begin{tabular}{|c|c|c|c|c|c|c|c|c|}
\hline \multirow{2}{*}{$\begin{array}{r}\text { Parcel } \\
\text { Code } \\
\end{array}$} & \multirow{2}{*}{$\begin{array}{l}\text { Parcel } \\
\text { Number }\end{array}$} & \multicolumn{6}{|c|}{ Factor ${ }^{b}$} & \multirow{2}{*}{ Communality } \\
\hline & & I & II & III & IV & $\mathrm{V}$ & $\mathrm{VI}$ & \\
\hline \multicolumn{9}{|l|}{ Verbal } \\
\hline $\mathrm{SC}$ & 1 & 54 & 20 & 33 & & & & 46 \\
\hline SC & 2 & 55 & & 32 & & & & 46 \\
\hline SC & 3 & 37 & & 48 & & & & 43 \\
\hline $\mathrm{SC}$ & 4 & 31 & & 61 & & & & 51 \\
\hline AN & 5 & 36 & & 55 & & & & 47 \\
\hline AN & 6 & 56 & & & & & & 39 \\
\hline AN & 7 & & & 69 & & & & 54 \\
\hline AN & 8 & & & 72 & & & & 55 \\
\hline OPP & 9 & & & 62 & & & & 41 \\
\hline OPP & 10 & & & 64 & & & & 43 \\
\hline OPP & 11 & 24 & & 67 & & & & 52 \\
\hline OPP & 12 & 27 & & 66 & & & & 55 \\
\hline OPP & 13 & 60 & & 31 & & & & 50 \\
\hline RCP1 & 14 & 58 & & & & & & 41 \\
\hline RCP2 & 15 & 37 & 36 & & & & & 34 \\
\hline RCP3 & 16 & 46 & & 30 & 22 & & & 37 \\
\hline RCP3 & 17 & 52 & & 22 & 22 & & & 39 \\
\hline RCP4 & 18 & 37 & 21 & 32 & 29 & & & 38 \\
\hline RCP5 & 19 & 26 & & 26 & 67 & & & 64 \\
\hline RCP5 & 20 & 33 & & & 68 & & & 66 \\
\hline \multicolumn{9}{|c|}{ Quantitative } \\
\hline QC & 21 & & 51 & & & & & 33 \\
\hline QC & 22 & 25 & 57 & & & & & 42 \\
\hline$Q C$ & 23 & & 56 & & & & & 38 \\
\hline QC & 24 & & 49 & & & & & 25 \\
\hline$Q C$ & 25 & & 56 & & & & & 36 \\
\hline QC & 26 & 30 & 55 & & & & & 39 \\
\hline$Q C$ & 27 & 35 & 52 & & & & & 40 \\
\hline QC & 28 & 30 & 44 & & & & & 30 \\
\hline DI & 29 & 35 & 41 & & & 23 & & 36 \\
\hline DI & 30 & 25 & 26 & & & 55 & & 46 \\
\hline DI & 31 & & 32 & & & 58 & & 50 \\
\hline Q & 32 & & 50 & & & & & 29 \\
\hline GEOM & 33 & & 71 & & & & & 58 \\
\hline ALG & 34 & & 44 & & & 22 & & 29 \\
\hline \multicolumn{9}{|l|}{ Word } \\
\hline Problems & 35 & 21 & 47 & & & 31 & & 41 \\
\hline
\end{tabular}

-continued on the next page- 
Table 3 , continued

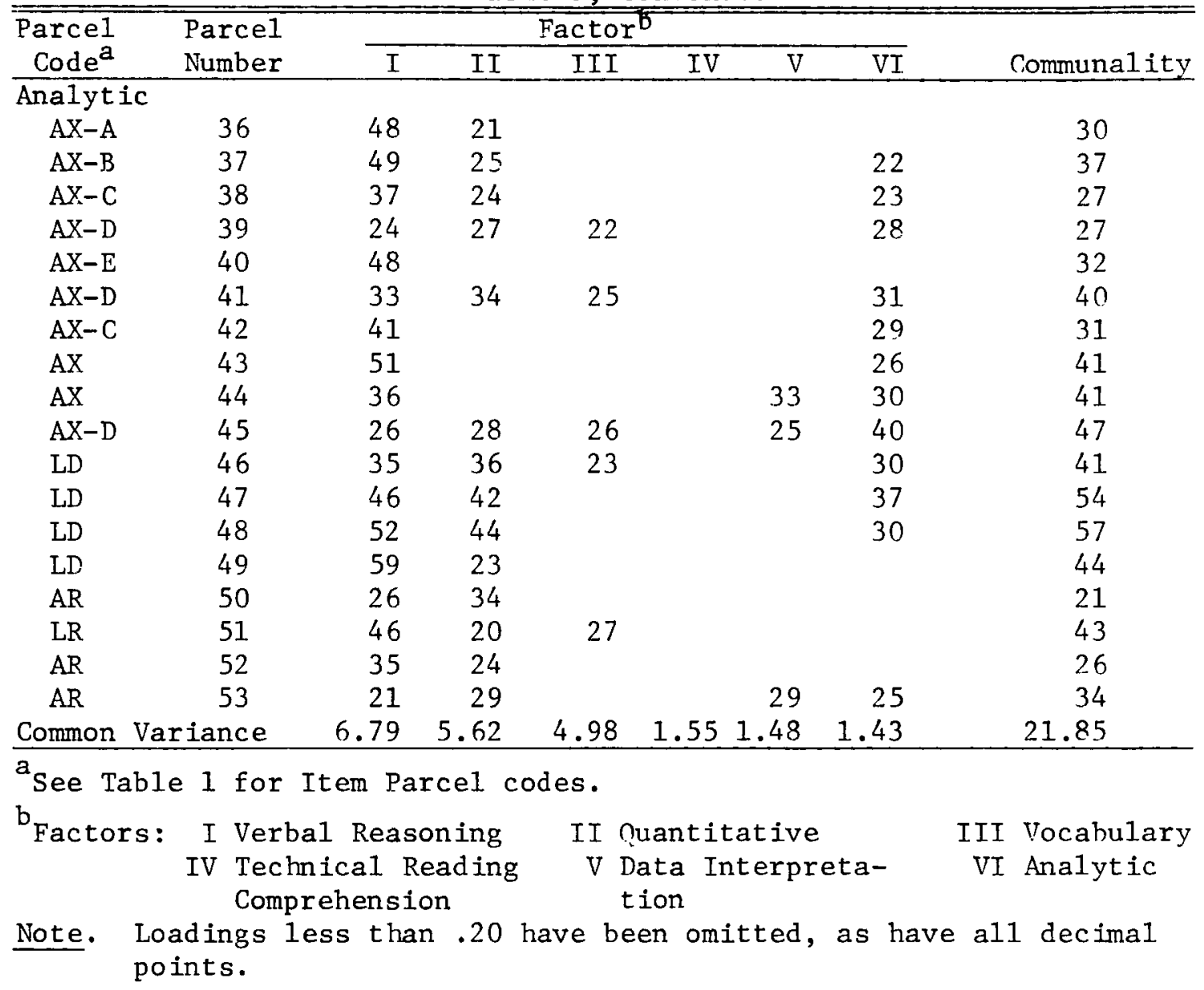

type. That is, the analytical items comprising the analytical section of the Aptitude Test appear to have more variance in common with a general comprehension or reasoning factor than with the minor analytical factor.

However, the restriction to orthogonal factors may result in an oversimplified representation of the test's structure. Since it is probably unreasonable to expect the abilities of various verbal, quantitative, and analytical item types to be independent or uncorrelated in the population of GRE test takers, an oblique geoplane solution was obtained.

\section{Geoplane Solution}

The results of the geoplane rotation of six factors are given in Table 4. Factor I', accounting for $18.3 \%$ of the common variance, was viewed as a "reading comprehension" factor because of its large loadings from reading passages, easier sentence completion items, and easy discrete verbal items. One negative and several near-zero loadings from difficult verbal items, principally the discrete types, supported the interpretation of this factor. 
Table 4

Geoplane Factor Pattern (Partial Correlations) for Item Parcel Analysis

\begin{tabular}{|c|c|c|c|c|c|c|c|c|}
\hline \multirow{2}{*}{$\begin{array}{l}\text { Parcel } \\
\text { Code }\end{array}$} & \multirow{2}{*}{$\begin{array}{l}\text { Parce1 } \\
\text { Number }\end{array}$} & \multicolumn{6}{|c|}{ Factor } & \multirow[b]{2}{*}{ Communality } \\
\hline & & $I^{\prime}$ & $I I^{\prime}$ & $\mathrm{III}^{\prime}$ & $I V^{\prime}$ & $\mathrm{V}^{\prime}$ & $\mathrm{VI}^{\prime}$ & \\
\hline \multicolumn{9}{|l|}{ Verbal } \\
\hline $\mathrm{SC}$ & 1 & 47 & & & & & & 44 \\
\hline SC & 2 & 54 & & & & & & 44 \\
\hline $\mathrm{SC}$ & 3 & 36 & & 30 & & & & 44 \\
\hline $\mathrm{SC}$ & 4 & & & 57 & & & & 52 \\
\hline $\mathrm{AN}$ & 5 & 38 & & 42 & & & & 47 \\
\hline AN & 6 & 47 & & & & & & 37 \\
\hline AN & 7 & & & 72 & & & & 56 \\
\hline AN & 8 & & & 70 & & & & 51 \\
\hline OPP & 9 & -25 & & 70 & & & & 40 \\
\hline OPP & 10 & & & 65 & & & & 42 \\
\hline $\mathrm{OPP}$ & 11 & 22 & & 65 & & & & 54 \\
\hline OPP & 12 & & & 72 & & & & 59 \\
\hline OPP & 13 & 67 & & & & & & 49 \\
\hline RCP1 & 14 & 59 & & & & & & 39 \\
\hline RCP2 & 15 & 43 & 33 & & & & & 36 \\
\hline RCP3 & 16 & 53 & & & & & & 37 \\
\hline RCP3 & 17 & 60 & & & & & & 39 \\
\hline RCP4 & 18 & 49 & & & & & & 39 \\
\hline RCP5 & 19 & 37 & & & & 31 & & 38 \\
\hline RCP 5 & 20 & 42 & & & & 41 & & 41 \\
\hline \multicolumn{9}{|c|}{ Quantitative } \\
\hline QC & 21 & & 56 & & & & & 35 \\
\hline QC & 22 & & 50 & & & & & 43 \\
\hline $\mathrm{QC}$ & 23 & & 63 & & & & & 40 \\
\hline QC & 24 & & 59 & & & & & 27 \\
\hline $\mathrm{QC}$ & 25 & & 51 & & & & & 37 \\
\hline QC & 26 & & 36 & & & & 27 & 37 \\
\hline QC & 27 & & 30 & & & & 31 & 37 \\
\hline QC & 28 & & & & & & 55 & 39 \\
\hline DI & 29 & 22 & & & & & 25 & 37 \\
\hline DI & 30 & & & & & 46 & & 35 \\
\hline DI & 31 & & & & & 43 & & 34 \\
\hline$Q$ & 32 & & 38 & & & & 30 & 31 \\
\hline GEOM & 33 & & 70 & & & & & 59 \\
\hline ALG & 34 & & 43 & & & 21 & & 30 \\
\hline \multicolumn{9}{|l|}{ Word } \\
\hline Probl & $\mathrm{ms} 35$ & & 38 & & & 23 & & 39 \\
\hline
\end{tabular}

-continued on the next page- 
Table 4, continued

\begin{tabular}{|c|c|c|c|c|c|c|c|c|}
\hline \multirow{2}{*}{$\begin{array}{c}\text { Parcel } \\
\text { Code }\end{array}$} & \multirow{2}{*}{$\begin{array}{l}\text { Parcel } \\
\text { Number }\end{array}$} & \multicolumn{6}{|c|}{ Factor ${ }^{2}$} & \multirow[b]{2}{*}{ Communal ity } \\
\hline & & $\overrightarrow{I^{\prime}}$ & $\mathrm{II}^{\prime}$ & $\operatorname{III}^{\prime}$ & IV & $\bar{V}^{\prime}$ & $\mathrm{VI}^{\prime}$ & \\
\hline \multicolumn{9}{|c|}{ Analytic } \\
\hline$A X-A$ & 36 & 27 & & & 23 & & & 29 \\
\hline$A X-B$ & 37 & & & & 44 & & & 38 \\
\hline$A X-C$ & 38 & & & & 30 & & & 27 \\
\hline$A X-D$ & 39 & & & & 24 & & & 25 \\
\hline$A X-E$ & 40 & 23 & & & 34 & & & $3 n$ \\
\hline$A X-D$ & 41 & & 22 & & 31 & & & 39 \\
\hline$A X-C$ & 42 & & & & 38 & & & 29 \\
\hline $\mathrm{AX}$ & 43 & & & & 38 & & & 38 \\
\hline $\mathrm{AX}$ & 44 & & & & 29 & 43 & & 41 \\
\hline$A X-D$ & 45 & & & & 32 & 39 & & 45 \\
\hline$L D$ & 46 & & 26 & & 38 & & & 41 \\
\hline LD & 47 & & 21 & & 54 & & & 52 \\
\hline LD & 48 & & & & 53 & & & 57 \\
\hline LD & 49 & 32 & & & 35 & & & 45 \\
\hline AR & 50 & & 27 & & & & & 22 \\
\hline LR & 51 & 34 & & & 21 & 20 & & 44 \\
\hline AR & 52 & 21 & & & & 22 & & 27 \\
\hline AR & 53 & & & & 20 & 46 & & 38 \\
\hline Common & ariance & 3.52 & 4.39 & 4.06 & 3.54 & 2.29 & 1.41 & 19.21 \\
\hline
\end{tabular}

${ }^{a}$ See Table 1 for Item Parcel codes.

bactors: I' Reading Comprehension IV' Analytic
II' General Quantitative

V'Data Interpretation/

Technical Comprehension
III' Vocabulary

VI' Filementary

nuantita-

tive

Note. Loadings less than .20 have been omitted, as have a11 decimal points.

Factor II' had high loadings from all of the quantitative parcels except those that were very easy and those that consisted of data interpretation items. This factor explained $22.8 \%$ of the test's common variance and is identified here as "general quantitative ability."

Factor III', reflecting $21.2 \%$ of the total common variance among parcels, was characterized nearly exclusively by very high loadings from all discrete verbal items except each of the very easiest antonym and analogy parcels. It also had two relatively high loadings from two difficult sentence completion parcels, which tend to have difficult vocabulary. This dimension was therefore interpreted to be a "vocabulary" factor.

Factor IV', which explained $18.4 \%$ of the parcels' common variance, received its highest loadings from parcels composed of items of the logical diagram analytical type, followed by analysis of explanation items. This factor appeared, then, to reflect a type of analytical ability.

Factor $\mathrm{V}^{\prime}$ explained $11.9 \%$ of the common variance. This factor is related to data interpretation parcels, the technical reading passages, and speed associated with several parcels of analyti- 
cal items located at the end of separately timed sections of the test. This factor is referred to here as data interpretation/technical comprehension, an ability that is apparently also associated with quickness in responding to analytical items. It should be noted that the analysis of explanation parcels that load on this factor have items based on a passage about hospital statistics, a passage that appears similar to data interpretation items and to the technical reading passage in content and style.

The final geoplane factor, Factor VI', reflected performance on several parcels of easy quantitative items. It accounted for $7.3 \%$ of the parcels' common variance and was termed easy or "elementary quantitative ability."

The intercorrelations among the geoplane factors (see Table 5) show a strong relationship ( $r$ $=.66$ ) between the reading comprehension and the analytical ability factors and substantial correlations (.54 and .56) between general quantitative and analytical ability and between reading comprehension and vocabulary. However, although correlated, the factors are distinct in their interpretation.

In summary, if one wishes to describe the structure of item parcels in terms of orthogonal factors, it appears that analytical items are primarily explained by a reading comprehension factor, to a somewhat lesser extent by quantitative ability, and to an even lesser extent by a minor dimension possessing a more distinctly analytical flavor. However, if one allows cor- related factors, the geoplane rotation identifies a distinct and more prominent, although strongly correlated, factor that reflects a component of analytical ability. This latter interpretation leaves open the possibility that the analytical and reading comprehension scales may yield differential predictive validity.

It is important to remember that correlated factors are involved here and that high factor pattern loadings represent those components of item variance unique to a factor. In an oblique solution, variables may exhibit higher pattern loadings on one factor although they may have higher correlations (factor structure coefficients) with another. Indeed, in the case of the geoplane solution, this is precisely what occurred with reading comprehension passages.

Table 6 gives the geoplane factor structure showing correlations of factors within the item parcels. Although reading passages have high pattern loadings (partial correlations) on Factor $I^{\prime}$ and near-zero loadings on Factor IV', examination of the projections (zero-order correlations) of the variables on the factors reveals that reading passages are slightly more highly correlated with Factor IV' than with Factor I', the "reading comprehension" factor. Thus, although Factor I' represents the dimension unique to reading passage items, it does not necessarily represent a typical reading passage item. The orthogonal varimax result, in which reading comprehension and analytical items loaded on a single general verbal reasoning factor, is thus

\section{Table 5}

Geoplane Factor Correlations

\begin{tabular}{|c|c|c|c|c|c|c|}
\hline \multicolumn{2}{|c|}{ Factor } & $\mathrm{I}^{\prime}$ & $\mathrm{II}^{\prime}$ & III' $^{\prime}$ & $\mathrm{IV}^{\prime}$ & $\bar{V}^{\prime}$ \\
\hline$\overline{\mathrm{I}^{\prime}}$ & Reading Comprehension & & & & & \\
\hline II' & Quantitative & .42 & & & & \\
\hline III' & Vocabulary & .56 & .37 & & & \\
\hline$I V^{\prime}$ & Analytic & .66 & .54 & .38 & & \\
\hline $\mathrm{V}^{\prime}$ & Data Interpretation/ & & & & & \\
\hline & Technical Comprehension & .51 & .50 & .41 & .42 & \\
\hline $\mathrm{VI}^{\prime}$ & Easy Quantitative & .34 & .36 & -.02 & .40 & .21 \\
\hline
\end{tabular}


Table 6

Geoplane Factor Structure (Zero-order Correlations) for Item Parcel Analysis

\begin{tabular}{|c|c|c|c|c|c|c|c|c|}
\hline \multirow{2}{*}{$\begin{array}{l}\text { Parce } \frac{1}{a} \\
\text { Code }\end{array}$} & \multirow{2}{*}{$\begin{array}{l}\text { Parcel } \\
\text { Number }\end{array}$} & \multicolumn{6}{|c|}{ Factor } & \multirow[b]{2}{*}{ Communa1ity } \\
\hline & & $\mathrm{I}^{\prime}$ & $I I^{\prime}$ & III' $^{\prime}$ & $I V^{\prime}$ & $\mathrm{V}^{\prime}$ & $\mathrm{VI}^{\prime}$ & \\
\hline \multicolumn{9}{|l|}{ Verbal } \\
\hline $\mathrm{SC}$ & 1 & 44 & 37 & 44 & 49 & 37 & 28 & 44 \\
\hline SC & 2 & 44 & 31 & 43 & 47 & 37 & 24 & 44 \\
\hline $\mathrm{SC}$ & 3 & 44 & 38 & 56 & 44 & 38 & & 44 \\
\hline $\mathrm{SC}$ & 4 & 52 & 34 & 69 & 40 & 37 & & 52 \\
\hline $\mathrm{AN}$ & 5 & 47 & 32 & 62 & 37 & 36 & & 47 \\
\hline AN & 6 & 37 & 29 & 32 & 46 & 31 & 32 & 37 \\
\hline AN & 7 & 56 & 33 & 75 & 33 & 33 & & 56 \\
\hline AN & 8 & 51 & 23 & 71 & 25 & 30 & & 51 \\
\hline OPP & 9 & 40 & 42 & 62 & 24 & 24 & & 40 \\
\hline $\mathrm{OPP}$ & 10 & 42 & 20 & 64 & 22 & 23 & & 42 \\
\hline OPP & 11 & 53 & 29 & 72 & 30 & 27 & & 54 \\
\hline $\mathrm{OPP}$ & 12 & 59 & 32 & 75 & 39 & 38 & & 59 \\
\hline OPP & 13 & 49 & 30 & 43 & 46 & 34 & 25 & 49 \\
\hline RCP1 & 14 & 39 & 26 & 32 & 45 & 29 & 27 & 39 \\
\hline $\mathrm{RCP} 2$ & 15 & 36 & 48 & 31 & 42 & 34 & 26 & 36 \\
\hline RCP3 & 16 & 37 & 27 & 41 & 43 & 33 & & 37 \\
\hline RCP3 & 17 & 39 & 25 & 34 & 41 & 37 & 20 & 39 \\
\hline $\mathrm{RCP} 4$ & 18 & 39 & 39 & 44 & 42 & 40 & & 39 \\
\hline RCP 5 & 19 & 38 & 35 & 40 & 35 & 52 & & 38 \\
\hline RCP 5 & 20 & 41 & 27 & 32 & 36 & 56 & & 41 \\
\hline \multicolumn{9}{|c|}{ Quantitative } \\
\hline $\mathrm{QC}$ & 21 & 35 & 58 & 22 & 36 & 28 & & 35 \\
\hline QC & 22 & 43 & 62 & 21 & 46 & 32 & 40 & 43 \\
\hline $\mathrm{QC}$ & 23 & 40 & 63 & 26 & 35 & 31 & & 40 \\
\hline QC & 24 & 27 & 50 & & & & & 27 \\
\hline $\mathrm{QC}$ & 25 & 37 & 59 & 24 & 35 & 30 & 36 & 37 \\
\hline $\mathrm{QC}$ & 26 & 37 & 52 & & 41 & 30 & 45 & 37 \\
\hline QC & 27 & 37 & 49 & & 43 & 26 & 49 & 37 \\
\hline $\mathrm{QC}$ & 28 & 39 & 37 & & 35 & 24 & 59 & 39 \\
\hline DI & 29 & 37 & 48 & 24 & 40 & 41 & 43 & 37 \\
\hline DI & 30 & 35 & 36 & 23 & 34 & 55 & 32 & 35 \\
\hline DI & 31 & 34 & 44 & 25 & 32 & 55 & 24 & 34 \\
\hline$Q$ & 32 & 31 & 49 & & 29 & 29 & 41 & 31 \\
\hline GEOM & 33 & 59 & 75 & 28 & 37 & 42 & 36 & 59 \\
\hline ALG & 34 & 30 & 51 & 20 & 31 & 40 & & 30 \\
\hline \multicolumn{9}{|l|}{$\begin{array}{l}\text { ALG } \\
\text { Word }\end{array}$} \\
\hline Prob & ms 35 & 39 & 57 & 28 & 40 & 48 & 31 & 39 \\
\hline
\end{tabular}

-continued on the next page- 
Table 6, continued

\begin{tabular}{|c|c|c|c|c|c|c|c|c|}
\hline \multirow{2}{*}{$\begin{array}{r}\text { Parcel } \\
\text { Code }\end{array}$} & \multirow{2}{*}{$\begin{array}{l}\text { Parcel } \\
\text { Number }\end{array}$} & \multicolumn{6}{|c|}{ Factor } & \multirow[b]{2}{*}{ Communality } \\
\hline & & $\bar{I}^{\prime}$ & $\mathrm{II}^{\prime}$ & III $^{\prime}$ & $\overline{I V^{\prime}}$ & $\mathrm{V}^{\prime}$ & $\overline{V I^{\prime}}$ & \\
\hline \multicolumn{9}{|c|}{ Analytic } \\
\hline$A X-A$ & 36 & 29 & 31 & 26 & 48 & 27 & 33 & 29 \\
\hline$A X-B$ & 37 & 38 & 36 & 24 & 60 & 31 & 34 & 38 \\
\hline$A X-C$ & 38 & 27 & 37 & 28 & 48 & 27 & & 27 \\
\hline$A X-D$ & 39 & 25 & 40 & 32 & 43 & 32 & & 25 \\
\hline$A X-E$ & 40 & 30 & 31 & 24 & 52 & 27 & 28 & 30 \\
\hline$A X-D$ & 41 & 39 & 49 & 39 & 55 & 41 & 20 & 39 \\
\hline$A X-C$ & 42 & 29 & 30 & 26 & 51 & 35 & & 29 \\
\hline $\mathrm{AX}$ & 43 & 38 & 34 & 29 & 57 & 40 & 29 & 38 \\
\hline$A X$ & 44 & 41 & 35 & 32 & 50 & 57 & 23 & 41 \\
\hline$A X-D$ & 45 & 45 & 46 & 40 & 52 & 58 & & 45 \\
\hline LD & 46 & 41 & 50 & 36 & 58 & 35 & 20 & 41 \\
\hline LD & 47 & 52 & 53 & 32 & 69 & 35 & 34 & 52 \\
\hline LD & 48 & 57 & 53 & 29 & 72 & 33 & 44 & 57 \\
\hline LD & 49 & 45 & 34 & 29 & 60 & 30 & 40 & 45 \\
\hline$A R$ & 50 & 22 & 41 & & 37 & 29 & 24 & 22 \\
\hline LR & 51 & 44 & 39 & 41 & 54 & 49 & 20 & 44 \\
\hline$A R$ & 52 & 27 & 34 & 21 & 43 & 41 & 25 & 27 \\
\hline $\mathrm{AR}$ & 53 & 38 & 42 & 32 & 42 & 58 & & 38 \\
\hline Common & riance & 3.52 & 4.39 & 4.06 & 3.54 & 2.29 & 1.41 & 19.21 \\
\hline
\end{tabular}

${ }^{a}$ See Table 1 for Item Parcel codes.

bactors: I' Reading II' Genera1 Quantitative
V' Data Interpretation/
Technical Comprehension

III' Vocabulary Comprehension IV'Analytic

VI' Elementary Quantitative

Note. Loadings less than .20 have been omitted, as have all decimal points.

not inconsistent with the geoplane description. Indeed, the pattern of correlations of geoplane Factors $I^{\prime}$ and $I^{\prime} V^{\prime}$ are both generally similar to that of the varimax verbal reasoning factor, the major difference being in the lower contribution of the latter from quantitative item parcels.

Geoplane Factor I' is seen as more closely correlated with discrete verbal items and less with analytical items than is Factor IV', analytical ability. The varimax general verbal reasoning factor, Factor I, can be thought of as being near the centroid of geoplane Factors I' and IV'. Then, the minor varimax analytical factor, Factor VI, defining a dimension of analytical ability orthogonal to reading comprehension, quantitative ability, and most analytical item variance, may be thought of as representing a dimension of contrast between the geoplane reading comprehension and the geoplane analytical ability factors. Thus, the varimax and geoplane "analytical" factors are not closely related, apparently tapping quite different aspects of analytical ability.

\section{Summary and Discussion}

From a factor analytic viewpoint, the goal of broadening the measurement of academic abil- 
ities beyond the verbal and quantitative domains appears to be attainable. The verbal and quantitative dimensions that underlie the restructured test remain quite similar to those reflecting performance on the original test. The two major verbal factors (vocabulary and reading comprehension) and the major quantitative factor extracted in this investigation correspond directly to the factors computed for the original test (Powers, Swinton, \& Carlson, 1977). This was expected, since except for the introduction of an additional quantitative item type, the verbal and quantitative types are the same for the new test as for the old one. Other less prominent verbal and quantitative dimensions related to item type and content of reading passages also remained quite similar for both tests. Results of this study suggest also that a distinct, identifiable analytical dimension has been introduced into the GRE Aptitude Test, although this factor is highly related to the other factors underlying performance on the test for the population of GRE candidates. This factor is defined predominately by the three new analytical item types but not by any of the verbal or quartitative item types.

One criticism of such omnibus verbal and quantitative ability measures as the GRE Aptitude Test is that they provide only a limited description of students' academic strengths and weaknesses (i.e., they do not adequately reflect either the diversity of candidates' backgrounds and experiences or their differential development in other important cognitive areas). The introduction of an analytical component to the test may serve to provide a more multidimensional definition of academic talent that may serve not only selection purposes but also guidance and placement functions. A more comprehensive picture of students' abilities seems especially appropriate for the GRE Aptitude Test, which must serve numerous graduate departments having very different orientations. Once the new measure is fully operational, its actual utility can be determined only by further monitoring its use and evaluating its impact.

\section{References}

Altman, R. A., Carlson, A. B., \& Donlon, T. F. Developing a plan for the renewal of the GRE morning test: $A$ report on investigations into the possible shortening of the GRE-V and GRE-Q and the creation of a modular aptitude test (GRE Report 74-3). Princeton, NJ: Educational Testing Service, 1975.

Altman, R. A., \& Conrad, L. Aptitude test restructuring research: Findings concerning changes in verbal and quantitative measures. Unpublished progress report to the GRE Board Research Committee, April 1976.

American Psychological Association. Standards for educational and psychological tests. Washington, DC: Author, 1974.

Carroll, J. B., \& Maxwell, S. E. Individual differences in cognitive abilities. Annual Review of Psychology, 1979, 30, 603-640.

Cattell, R. B. The scree test for the number of factors. Multivariate Behavioral Research, 1966, I, 245-276.

Cattell, R. B., \& Burdsal, C. A. The radial parcel double factoring design: A solution of the item-vsparcel controversy. Multivariate Behavioral Research, 1975, 10, 65-179.

Conrad, L. Aptitude test restructuring research: Findings concerning projected development of an abstract reasoning measure (GRE Technical Report). Princeton, NJ: Educational Testing Service, 1976.

Conrad, L., Trismen, D., \& Miller, R. (Eds.). Graduate Record Examinations technical manual. Princeton, NJ: Educational Testing Service, 1977.

Cronbach, L. J. Test validation. In R. L. Thorndike (Ed.), Educational measurement (2nd ed.). Washington, DC: American Council on Education, 1971.

Dwyer, P.S. The determination of the factor loadings of a given test from the known loadings of the tests. Psychometrika, 1937, 2, 173-178.

Harman, H. H. Extensions of factorial solutions. Psychometrika, 1938, 3, 75-84.

Harman, H. H. Modern factor analysis (3rd ed.). Chicago: The University of Chicago Press, 1976.

Harman, H. H., \& Jones, W. H. Factor analysis by minimizing residuals (minres). Psychometrika, 1966, 31, 351-368.

Jennrich, R. I., \& Sampson, P. F. Rotation for simple loadings. Psychometrika, 1966, 31, 313-323.

Kaiser, H. F. The varimax criterion for analytic rotation in factor analysis. Psychometrika, 1958, 23, 187-200. 
Powers, D. E., Swinton, S. S., \& Carlson, A. B. A factor analytic study of the GRE Aptitude Test (GRE Board Professional Report 75-11P). Princeton, NJ: Educational Testing Service, 1977.

Swinton, S. S., \& Powers, D. E. A factor analytic study of the restructured GRE Aptitude Test (GRE Board Professional Report No. 77-6P). Princeton, NJ: Educational Testing Service, 1979.

Willingham, W. W. Predicting success in graduate education. Science, 1974, 183, 273-278.

Willingham, W. W. Validity of the Graduate Record Examinations. Princeton, NJ: Educational Testing Service, 1976.

Wilson, K. M. The validation of GRE scores as predictor of first-year performance in graduate study: Report of the GRE Cooperative Validity Studies Project (75-8). Princeton, NJ: Educational Testing Service, 1979.

Yates, A. An oblique transformation method for primary factor pattern simplification, which permits factorial complexity in exploratory analyses. Paper presented at the annual meeting of the Psychometric Society, Palo Alto, April 1974.

Yates, A. Geomin transformation: Primary oblique factor pattern which permits factorial complexity in exploratory analysis. Unpublished doctoral dissertation, Bowling Green University, 1978.

Yates, A. Multivariate exploratory data analyses: True exploratory factor analysis. Los Angeles: UCLA, 1979.

\section{Acknowledgments}

This paper is based on a presentation given at the annual meeting of the National Council in Measurement in Education (NCME), San Francisco, 1979. The authors acknowledge the support of the Graduate Record Examinations Board in conducting this research, and that of Bert Green for helpful comments. Dorothy Thayer for programming the analyses, and Chris Rushinski for typing the report.

\section{Author's Address}

Send requests for reprints or further information to Donald E. Powers, Educational Testing Service, Princeton, NJ 08541. 